\title{
ANALYSIS OF THE DIAGNOSTIC POTENTIAL THERMOVISION RESEARCH IN THE TECHNICAL CONDITION ASSESSMENT OF SPARK IGNITION ENGINES INJECTORS
}

\author{
Kałaczyński T.*, Lukasiewicz M..*, Musial J..**, Liss M. ${ }^{* * * *}$, Kasprowicz T. ${ }^{* * * * *}$
}

\begin{abstract}
The paper presents an analysis of the possibilities of implementing thermographic tests in the process of assessing the technical condition of spark-ignition internal combustion engines. Presented method is an innovative approach to diagnosing the condition of injectors used in spark-ignition internal combustion engines. Presented non-installation method of assessment injectors technical state uses measurements of accompanying processes such as heat generation by their working elements. The use of thermovision cameras allows direct verification of the injectors state. The work is a continuation of the implementation of thermovision tests in the assessment of the technical condition of internal combustion engines implemented by the authors.
\end{abstract}

Keywords: Technical state, Diagnostics, Thermovision, Injector, Fuel supply system.

\section{Introduction}

The design of modern internal combustion engines is focused on material, strength, economic and environmental optimization (Lukasiewicz et al., 2014). Performing multi-criteria optimization is a challenge for designers of spark ignition engines used in modern motor vehicles due to the need to achieve a balance between user expectations focused on operating parameters and economy, and stringent exhaust emission standards and guidelines in terms of environmental protection (Muślewski et al., 2018). This is a need to modify existing design solutions used in spark-ignition internal combustion engines or to attempt to create an innovative solution that fulfil the above-mentioned requirements (Kałaczyński et al., 2018).

One of the solutions is the analysis of the combustion process of the air-fuel mixture, the optimal qualitative and quantitative composition of which affects the phenomena occurring in the spark-ignition internal combustion engine. The correct fuel dose and its atomization play a very important role in the combustion process.

An important element of the fuel supply systems used in spark-ignition internal combustion engines responsible for controlling the quality of fuel supplied to the cylinders are injectors. Attention should be paid to the problem of diagnostic susceptibility of working elements used in fuel supply systems for internal combustion engines. The process of assessing the technical condition of injectors consists mainly of disassembly and verification of injectors at measuring stations. It is a time-consuming method and requires specialized equipment. Therefore, there is a need to propose an innovative method of assessing the technical condition of injectors that would allow non-invasive assessment of the condition of injectors in sparkignition engines.

Tomasz Kałaczyński, PhD.: Faculty of Mechanical Engineering, University of Science and Technology, Al. prof. S. Kaliskiego 7, Bydgoszcz; PL, kalaczynskit@utp.edu.pl

** $\quad$ Marcin Łukasiewicz, PhD.: Faculty of Mechanical Engineering, University of Science and Technology, Al. prof. S. Kaliskiego 7, Bydgoszcz; PL, mlukas@utp.edu.pl

*** Prof. Janusz Musiał, PhD.: Faculty of Mechanical Engineering, University of Science and Technology, Al. prof. S. Kaliskiego 7, Bydgoszcz; PL, jamusual@utp.edu.pl

***** Michał Liss, PhD.: Faculty of Mechanical Engineering, University of Science and Technology, Al. prof. S. Kaliskiego 7, Bydgoszcz; PL, michal.liss@utp.edu.pl

****** Tomasz Kasprowicz, M.Sc.: Faculty of Mechanical Engineering, University of Science and Technology, Al. prof. S. Kaliskiego 7, Bydgoszcz; PL, kasprowicz.tomasz@gmail.com 
Research carried out in the field of implementing thermal imaging tests for assessing the technical condition of internal combustion engines by the research team being the authors of this publication clearly indicates that thermal imaging tests are a good non-dismantling method for assessing the technical condition of technical objects. This method uses a special type of television that records the heat emitted by objects in its field of vision, more precisely - the emission of infrared radiation. By measuring the infrared radiation emitted by a given body, we measure its temperature (Łukasiewicz et al., 2018). The diagnostic potential of thermovision tests should be assessed in assessing the condition of the spark-ignition internal combustion engine injectors.

\section{Methods}

The variety of solutions for the design variants of the power supply systems is a difficulty in implementing traditional diagnostic methods. Considering the multifunctionality of fuel supply systems regarding the mixture, emissivity and optimization of operating parameters, it generates the need for continuous verification of the technical condition of actuators, which are undoubtedly injectors (Landowski et al., 2017).

Analysis of the scope of use of injectors in fuel supply systems used in spark-ignition internal combustion engines indicates that the most used injectors are electromagnetic injectors. Verification of the principle of operation of electromagnetic injectors, which depends directly on the control currents, indicates the need for correct response of the injector components to the setpoints (Heiko, 2016). Damaged injectors generate incorrect work of internal combustion engines with spark ignition which adversely affect the achievement of the required values of operating parameters and the environment (Ligaj et al., 2016).

The paper presents the implementation of the injector condition assessment procedure based on thermovision measurements. Stand tests were carried out at the stand for verification and cleaning of electromagnetic injectors LUNCH INJECTIOR CLEANER \& TEST shown in Fig. 1. This position enables verifications at which time duty cycle, the injector coil begins to work, the way fuel atomization, test to overflow, leak test and conduct ultrasonic cleaning of injectors.
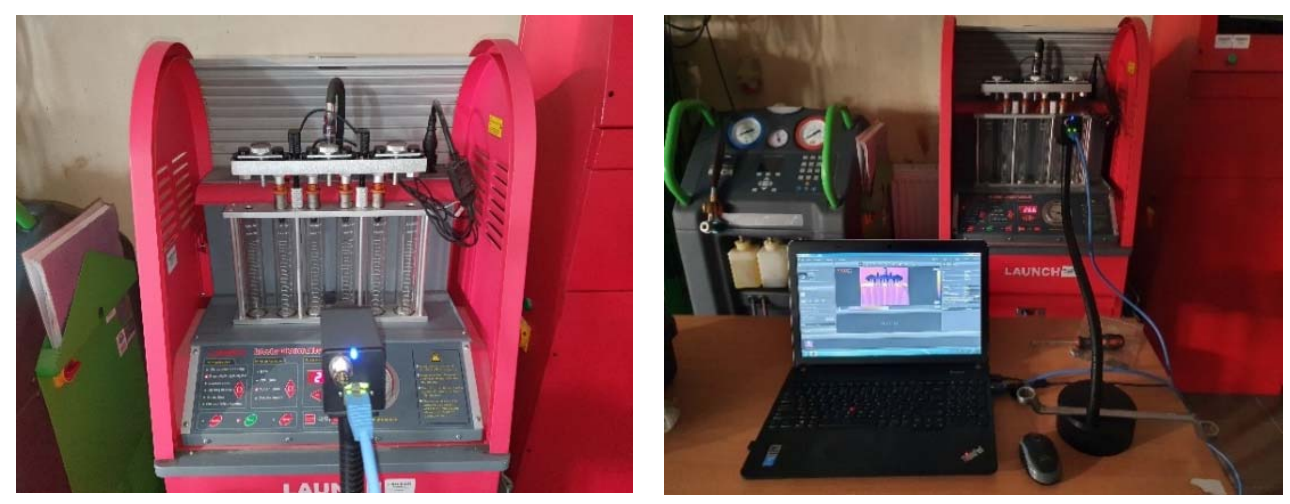

The test stand was equipped with petrol injectors from a Nissan X-trail vehicle used in $2500 \mathrm{cc}$ engines, while the test stand was equipped with a FLIR AX5 camera for continuous thermal imaging measurements.

Fig. 1: Research stand.

Based on the initial tests, the test conditions were established: - ambient temperature $25^{\circ} \mathrm{C}$, - measuring distance $50 \mathrm{~cm},-2.4 \mathrm{~ms}$ injection time, - rotation speed $800 \mathrm{rpm}$. First, the condition of the injectors was verified by overflow test. The measurements showed that the injector No. 4 gives much less fuel, which may indicate that it is dirty. The measurement results are shown in Tab. 1.

Tab 1: Results of the overflow test.

\begin{tabular}{|c|c|c|c|c|}
\hline Test & Injector 1 & Injector 2 & Injector 3 & Injector 4 \\
\hline 1 & $60 \mathrm{ml}$ & $62 \mathrm{ml}$ & $59 \mathrm{ml}$ & $45 \mathrm{ml}$ \\
\hline 2 & $61 \mathrm{ml}$ & $60 \mathrm{ml}$ & $61 \mathrm{ml}$ & $48 \mathrm{ml}$ \\
\hline
\end{tabular}

Then, thermographic measurements were carried out during the operation of the injectors according to the following methodology. The injection system was running for $20 \mathrm{~min}$. During the work, the injector temperature was read every 5 minutes. Readings were taken in three measurement series; the results are presented in Tab. 2. 
Tab. 2: Temperature measurement results.

\begin{tabular}{|c|c|c|c|c|c|c|c|c|c|c|c|c|c|c|c|c|c|}
\hline \multicolumn{10}{|c|}{ series I } & \multicolumn{10}{|c|}{ series III } \\
\hline $\begin{array}{c}\text { Time } \\
(\mathrm{min})\end{array}$ & 0 & 5 & 10 & 15 & 20 & $\begin{array}{c}\text { Time } \\
(\mathrm{min})\end{array}$ & 0 & 5 & 10 & 15 & 20 & $\begin{array}{c}\text { Time } \\
(\mathrm{min})\end{array}$ & 0 & 5 & 10 & 15 & 20 \\
\hline I & 25.6 & 30.2 & 31.5 & 33.8 & 35.5 & I & 25.8 & 30.2 & 31.8 & 33.3 & 35.4 & I & 25.1 & 30.1 & 31.4 & 33.9 & 35.7 \\
\hline II & 25.4 & 29.9 & 31.9 & 34.0 & 34.8 & II & 25.7 & 29.9 & 32.2 & 34.1 & 34.9 & II & 25.2 & 29.8 & 31.7 & 34.2 & 34.9 \\
\hline III & 25.5 & 30.5 & 32.2 & 34.5 & 35.2 & III & 25.6 & 30.5 & 32.6 & 34.3 & 35.5 & III & 25.2 & 30.6 & 32.4 & 34.4 & 35.3 \\
IV & 25.4 & 32.1 & 36.4 & 38.3 & 45.2 & IV & 25.9 & 32.1 & 36.9 & 38.7 & 45.4 & IV & 24.9 & 32.5 & 36.6 & 38.7 & 45.6 \\
\hline
\end{tabular}

The results of thermographic measurements clearly confirm that there is a relationship between damage to the injector and its operating temperature. The test stand made it possible to carry out an injector cleaning test. After cleaning and overflow test, the injector showed the same parameters as efficient injectors during the first test. The results of the overflow test after cleaning are shown in Tab. 3.

Tab. 3: Results of the overflow test after cleaning.

\begin{tabular}{|c|c|c|c|c|}
\hline Test & Injector 1 & Injector 2 & Injector 3 & Injector 4 \\
\hline 1 & $60 \mathrm{ml}$ & $62 \mathrm{ml}$ & $59 \mathrm{ml}$ & $58 \mathrm{ml}$ \\
\hline 2 & $61 \mathrm{ml}$ & $60 \mathrm{ml}$ & $61 \mathrm{ml}$ & $59 \mathrm{ml}$ \\
\hline
\end{tabular}

Then the thermographic tests on the injectors were repeated to verify the temperature of the injector after regeneration, the test results are presented in Tab. 4.

Tab. 4: Results of temperature measurements after regeneration.

\begin{tabular}{|c|c|c|c|c|c|c|c|c|c|c|c|c|c|c|c|c|c|}
\hline \multicolumn{10}{|c|}{ series II } \\
\multicolumn{10}{|c|}{ camera FLIR AX5 } \\
\hline \multicolumn{10}{|c|}{ I } \\
\hline $\begin{array}{c}\text { Time } \\
\text { (min) }\end{array}$ & 0 & 5 & 10 & 15 & 20 & $\begin{array}{c}\text { Time } \\
\text { (min) }\end{array}$ & 0 & 5 & 10 & 15 & 20 & $\begin{array}{c}\text { Time } \\
(\mathrm{min})\end{array}$ & 0 & 5 & 10 & 15 & 20 \\
\hline I & 25.3 & 30.3 & 31.4 & 33.7 & 35.4 & I & 25.7 & 30.3 & 31.7 & 33.4 & 35.5 & I & 25.2 & 30.3 & 31.8 & 33.3 & 35.6 \\
\hline II & 25.5 & 29.5 & 31.5 & 34.1 & 34.7 & II & 25.6 & 29.8 & 32.3 & 34.3 & 34.8 & II & 25.3 & 29.7 & 31.6 & 34.7 & 34.8 \\
\hline III & 25.2 & 30.7 & 32.7 & 34.6 & 35.3 & III & 25.5 & 30.6 & 32.8 & 34.6 & 35.4 & III & 25.5 & 30.5 & 32.5 & 34.8 & 35.4 \\
\hline IV & 25.4 & 30.4 & 32.4 & 34.6 & 35.5 & IV & 25.9 & 30.1 & 32.9 & 34.7 & 35.4 & IV & 24.9 & 30.4 & 32.5 & 34.3 & 35.4 \\
\hline
\end{tabular}

Analysis of the obtained results allows to determine the accuracy of the measuring device, as well as to verify the dependence of the temperature gradient increase at the measuring points. The test results presented in the tables are measurements at the selected point. Detailed analysis requires propagation of thermal energy flow in the injector based on the analysis of thermographic images. Fig. 2 presents selected results of thermovision examinations of injectors. FLIR Tools software was used to analyse thermographic images. The main software dialog window is shown in Fig. 3.

\section{Conclusions}

The paper presents the process of verifying the technical condition of injectors with the use of thermovision tests, which were verified to confirm the results of the tests. The implementation of thermal imaging tests makes the temperature correlation unambiguous with the change in the technical condition of the injectors being components of internal combustion engines. The method of thermovision testing is an ideal tool that 
can be used in an innovative methodology for assessing the technical condition of spark-ignition internal combustion engines. There is a need to improve thermal imaging tests in the areas of technical object assessment and to develop diagnostic procedures considering the minimum acquisition and validation of measurement data aimed at increasing the operational efficiency and reliability of technical objects.

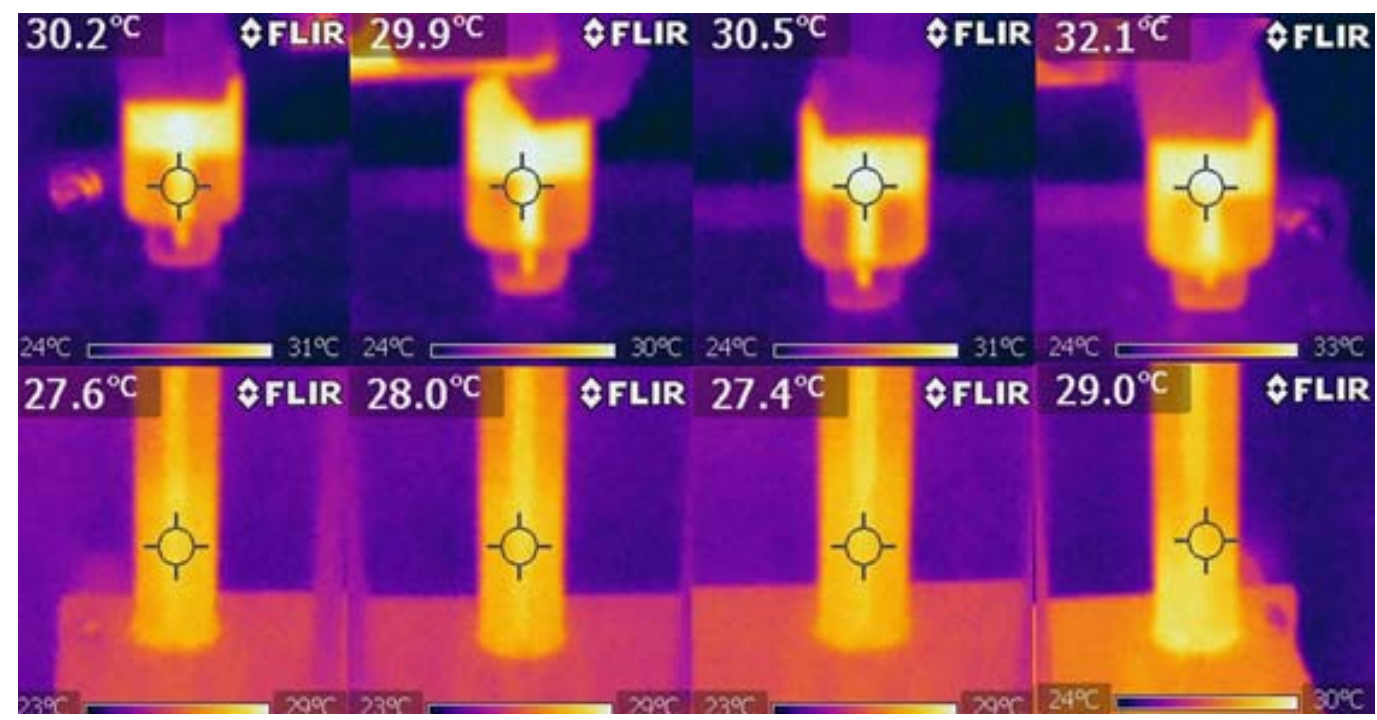

Fig. 2: Selected test results for the thermovision camera.

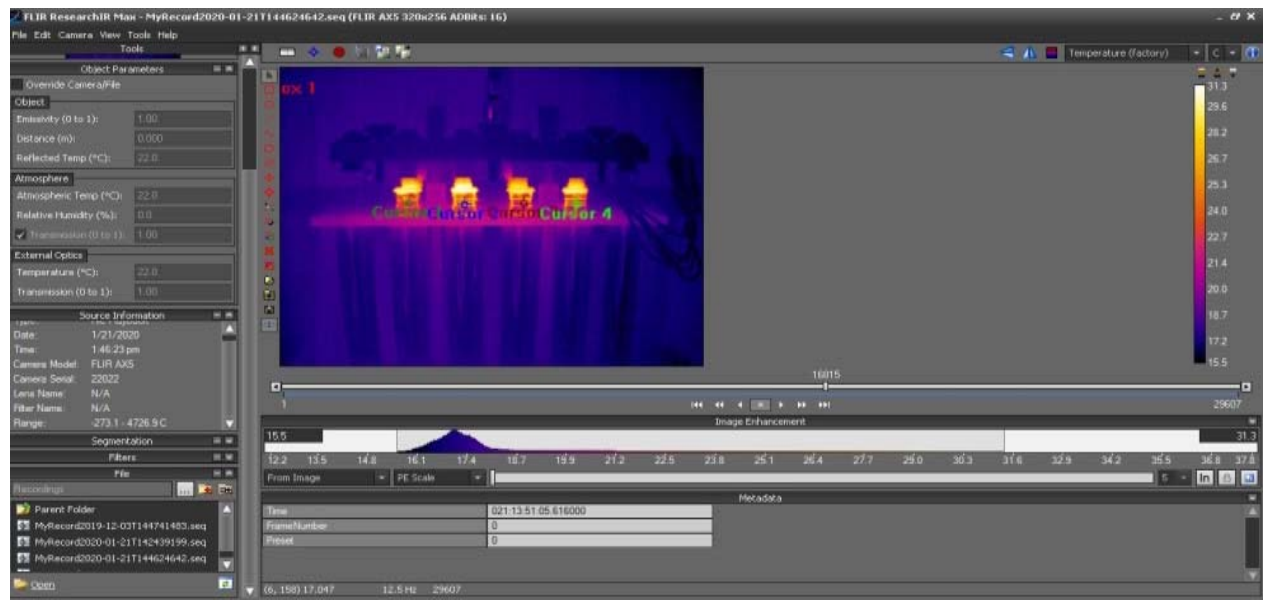

Fig. 3: The main FLIR Tools software dialog box.

\section{References}

Heiko P. (2016) Petrol direct injection systems in workshop practice, Wydawnictwo Komunikacji i Łączności, Warszawa, (in Polish).

Kałaczyński T., Łukasiewicz M., Musiał J., Polasik R., Szczutkowski M., Dluhunovych N., Wilczarska J., Kasprowicz T. (2018) Analysis of the diagnostic potential research thermovision in the technical state of combustion engine injectors assessment. $24^{\text {th }}$ Inter. Conf. Engineering Mechanics vol. 24, pp. 357-360.

Landowski B., Pająk M., Żółtowski B., Muślewski Ł. (2017) Method of building a model of operational changes for the marine combustion engine describing the impact of the damages of this engine on the characteristics of its operation process. Polish Maritime Research 2017, nr 4 (96), vol. 24; pp. 67-76.

Ligaj B., Sołtysiak R. (2016) Problems of Equivalent Load Amplitude in Fatigue Life Calculations, Polish Maritime Reseaech, vol. 23, iss. 1, pp. 85-92, doi:10.1515/pomr-2016-0012.

Łukasiewicz M., Kałaczyński T., Musiał J., Shalapko J. (2014) Diagnostics of buggy vehicle transmission gearbox technical state based on modal vibrations. Journal of Vibroengineering, nr. 16, vol. 6, pp. 3137-3145.

Łukasiewicz M., Falęcki P., Kałaczyński T., Żółtowski B., Musiał J., Wilczarska J., Kostek R. (2018) Analysis of the thermovision diagnostics potential in the light system elements. $24^{\text {th }}$ Inter. Conf. Engineering Mechanics vol. 24, pp. 513-516.

Muślewski Ł., Pająk M., Grządziela A., Musiał J. (2015) Analysis of vibration time histories in the time domain for propulsion systems of minesweepers Journal of Vibroengineering, vol. 17, iss. 3, pp. 1309-1316. 